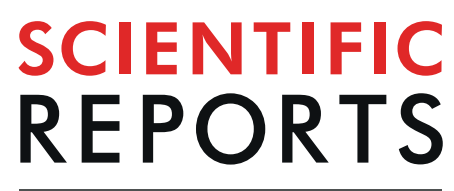

natureresearch

\title{
Revealing the constituents of Egypt's oldest beer using infrared and mass spectrometry
}

\begin{abstract}
Mohamed A. Farag ${ }^{1,2}$, Moamen M. Elmassry ${ }^{3}$, Masahiro Baba ${ }^{4 *}$ \& Renée Friedman ${ }^{5}$
Previous studies have shown that the Ancient Egyptians used malted wheat and barley as the main ingredients in beer brewing, but the chemical determination of the exact recipe is still lacking. To investigate the constituents of ancient beer, we conducted a detailed IR and GC-MS based metabolite analyses targeting volatile and non-volatile metabolites on the residues recovered from the interior of vats in what is currently the world's oldest (c. $3600 \mathrm{BCE}$ ) installation for large-scale beer production located at the major pre-pharaonic political center at Hierakonpolis, Egypt. In addition to distinguishing the chemical signatures of various flavoring agents, such as dates, a significant result of our analysis is the finding, for the first time, of phosphoric acid in high level probably used as a preservative much like in modern beverages. This suggests that the early brewers had acquired the knowledge needed to efficiently produce and preserve large quantities of beer. This study provides the most detailed chemical profile of an ancient beer using modern spectrometric techniques and providing evidence for the likely starting materials used in beer brewing.
\end{abstract}

Together with bread, beer was considered a staple food for the ancient Egyptians. Moreover, it was an essential provision for their afterlife as shown by numerous depictions and models of brewing found in their tombs. The archaeological record indicates that beer production dates back before the pharaoh, to the Predynastic period (4000-3100 BCE (Before Common Era)), which is the formative stage of the Egyptian civilization. Heating installations related to beer production involving large ceramic vats (serving as mashtuns) have been reported at several sites of this era ${ }^{1,2}$, with a significant number detected by excavation and remote sensing at the major population center of ancient Hierakonpolis ${ }^{3}$. Hierakonpolis is located on the west bank of the Nile, $17 \mathrm{~km}$ north of the modern town of Edfu in Upper Egypt (Fig. 1A). Stretching for over $3 \mathrm{~km}$ along the Nile, it is one of the largest sites of the Predynastic period ${ }^{3}$. Excavations in a part of the site known as locality HK11C revealed a well-preserved brewery establishment consisting of five freestanding ceramic vats placed beside low wall segments (Fig. 1B) ${ }^{4}$. Only the lower parts of the vats are preserved, but the remains still stand to a height of 40 to $60 \mathrm{~cm}$ with diameters ranging from 60 to $85 \mathrm{~cm}$ (Fig. 1C). The vat exteriors had been coated with mud and pottery sherds to protect from thermal shock and promote even heating, and a ring of large sherds cemented together with mud placed around the base aided stability and enclosed the fire. Rubification of the construction materials and the high amount of charcoal and ash in the surroundings leave no doubt that these vats functioned as heating installations.

Adhering to the interior of each vat was a thick layer (up to $3 \mathrm{~cm}$ ) of residue with a shiny black skin. Botanical examinations of the residue indicated that the main ingredients were emmer wheat with some barley. These grains were coarsely crushed or ground and then heated in water together with grains that had been malted in their husks ${ }^{5}$. In addition, the scanning electron microscopy analysis revealed the presence of starch grains with perforation suggestive of enzymatic action prior to fermentation ${ }^{5}$. These findings indicate that the vats served to prepare the wort, the final product being beer. Radiocarbon testing of a sample of residue provides a date of 3764-3537 calibrated BCE (2 sigma) $\left({ }^{14} \mathrm{C} 4875 \pm 40\right.$ Before Present $\left.(\mathrm{BP})\right)$, make this installation the oldest dated brewery in Egypt. Calculating from the size and number of the vats, a total of 325 liters of beer could have been produced at one time. This quantity, roughly equivalent to 650 modern bottles, indicates a scale of production, undocumented elsewhere in the world at this time. Moreover, integrated into the brewing facility were several pottery kilns to fire the jars that contained the brew (Fig. 1B).

${ }^{1}$ Pharmacognosy Department, Faculty of Pharmacy, Cairo University, Cairo, 11562, Egypt. 2Departmenst of Chemistry, School of Sciences \& Engineering, The American University in Cairo, New Cairo, 11835, Egypt. ${ }^{3}$ Department of Biological Sciences, Texas Tech University, Lubbock, TX, USA. "Waseda Institute for Advanced Study, Waseda University, Tokyo, Japan. ${ }^{5}$ The Griffith Institute, University of Oxford, Oxford, UK. *email: m.baba@aoni.waseda.jp 

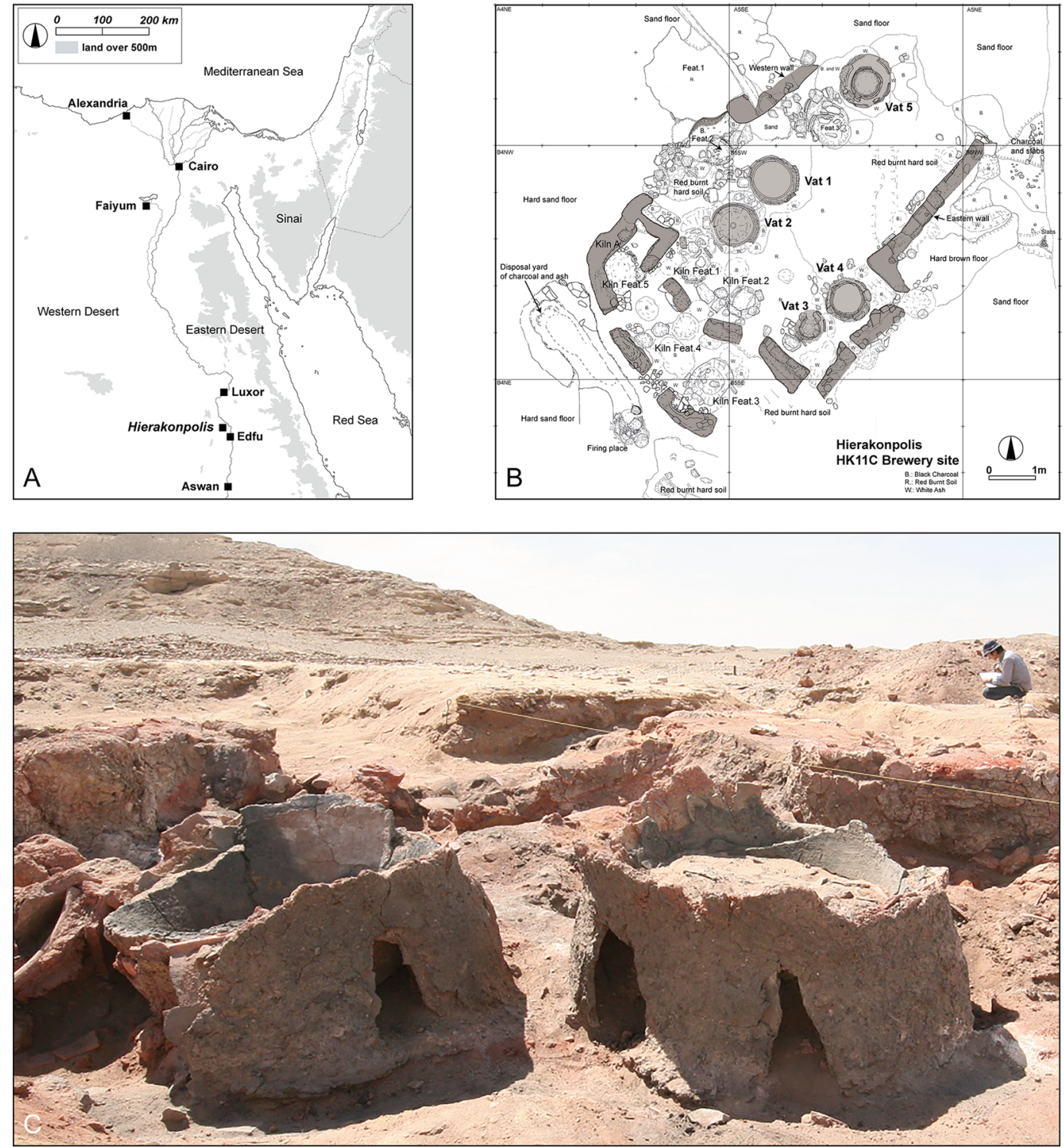

Figure 1. The excavation site at locality HK11C, Hierakonpolis. (A) General map of Egypt showing location of Hierakonpolis; (B) Plan of the heating installation; (C) Vats 1 and 2 viewed from the northeast. (A,B) created by Masahiro Baba using Adobe Illustrator; $(\mathbf{C})$ photo by Masahiro Baba.

Herein, our chemical analysis aims to provide insight on the brewing method and the product composition of this ancient beer. To comprehensively assess the constituents of the solid residue derived from the vats, we utilized a sensitive mass spectrometric approach. Four samples from two vats were subjected to analysis for their volatile components, directly using solid phase microextraction (SPME) coupled to gas chromatography-mass spectrometry (GC-MS) versus analysis of non-volatile primary metabolites viz., sugars, amino acids and organic acids using GC-MS post-silylation.

\section{Results and Discussion}

GC-MS and IR analysis of primary metabolites in the beer residue. 45 Compounds belonging to 11 chemical classes of metabolites were identified in the beer residue. Most abundant were inorganic (31.7\%), acids (27.8\%), and amino acids (27.4\%) (Fig. 2A,B, Table 1). Other chemical classes comprised nitrogenous compounds, fatty acids, aromatics, alcohols, ethers, sugars, aldehydes, and mono glyceryl ethers, although these were present at much lower levels. Phosphoric acid, one of the detected inorganics, was found at high levels (26.7\%) in comparison with other identified metabolites in all samples. This was confirmed using infrared (IR) analysis that showed bands indicative of phosphoric acid (Fig. 2). These bands corresponded to the following functional groups and their wave numbers: $\mathrm{P}-\mathrm{H}\left(\mathrm{PO}_{4}^{-3}\right), 2360-2368 \mathrm{~cm}^{-1} ; \mathrm{OH}\left(\mathrm{PO}_{4}^{-3}\right), 1625-1627 \mathrm{~cm}^{-1} ; \mathrm{P}=\mathrm{O}\left(\mathrm{PO}_{4}^{-3}\right)$, $1106 \mathrm{~cm}^{-1}$; P-O $\left(\mathrm{PO}_{4}{ }^{-3}\right), 1035-1037 \mathrm{~cm}^{-1}$; P-C $\left(\mathrm{PO}_{4}{ }^{-3}\right), 779 \mathrm{~cm}^{-1}$; and $\mathrm{PO}_{4}{ }^{-3}, 530-541 \mathrm{~cm}^{-1}$ (Fig. 3). Today phosphoric acid is a common additive to alcoholic and non-alcoholic beverages and is employed to prolong their shelf life and enhance flavor ${ }^{6-8}$. This is the first time such a high abundance of phosphoric acid has been detected in 
A

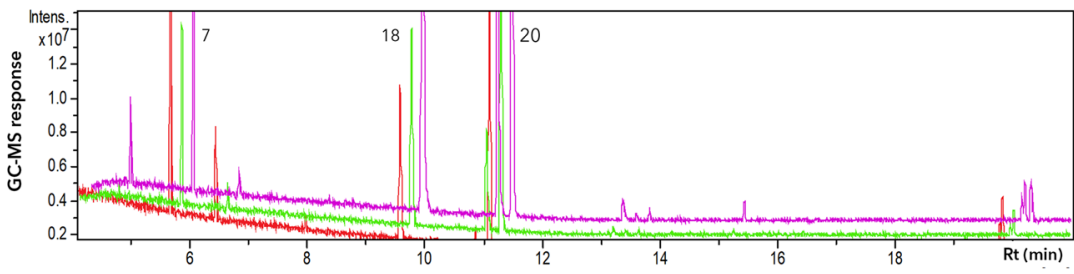

B
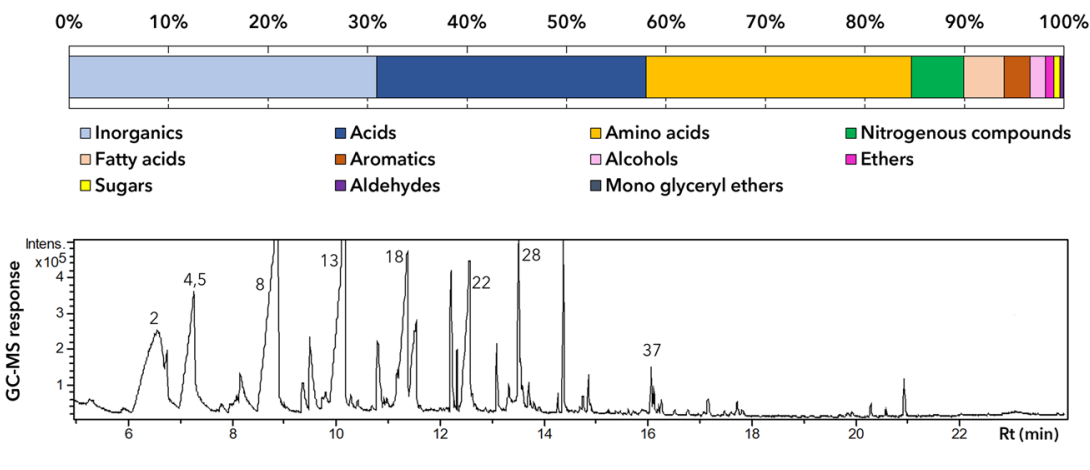

D $\quad 0 \%$

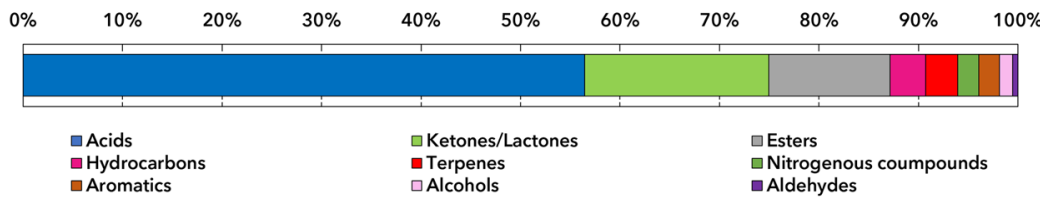

Figure 2. Metabolites analysis of the beer resides from the vats. (A) Representative overlaid chromatograms of non-volatile primary metabolites in vats analyzed as silylated products; (B) Relative percentage of chemical classes of compounds in beer residue samples as analyzed using GC-MS for non-volatiles analysis post silylation; (C) Representative GC-MS chromatogram of headspace volatiles collected from vats; (D) Relative percentage of chemical classes of volatile compounds in beer residue samples as analyzed using GC-MS.

ancient Egyptian beer ${ }^{9}$. The source of phosphoric acid is yet to be determined conclusively. However, it is likely that barley grains, which are rich in readily soluble phosphoric acid, are the source for this acid in the beer residue $^{10,11}$. It is possible that the ancient Egyptians utilized the phosphoric acid in barley as a food preservation, much in the same as hops is currently used to impart a flavor and for its preservative effect during beer fermentation $^{12}$. Previously, the earliest evidence of phosphoric acid was from two tripod cooking pots from Crete dating to around $1700 \mathrm{BCE}$ where it was found together with dimethyl oxalate, a basic constituent of modern beer ${ }^{13}$.

Twenty-two Organic acids were detected accounting for $27.8 \%$ of the primary metabolites pool in the beer residue. IR analysis confirmed bands indicative of organic acids from their respective wave numbers: $\mathrm{OH}$ (acid), $3403-3423 \mathrm{~cm}^{-1} ; \mathrm{C}=\mathrm{O}$ (acid), $1706-1708 \mathrm{~cm}^{-1}$; and $\mathrm{C}-\mathrm{O}$ (acid), 1319-1321 cm $\mathrm{cm}^{-1}$ and in accordance with GC-MS results (Fig. 3). Succinic acid was the predominant organic acid detected at $7.3 \%$, which is in agreement with what is described in modern beer post-fermentation ${ }^{14}$. Succinic acid is usually found at low levels in barley, but it accumulates with yeast fermentation, as does lactic acid, which was detected at $3.1 \%{ }^{15}$. Oxalic acid, which is commonly found in modern beer ${ }^{16}$ and is used as a marker for identifying ancient barely-beer fermenta$\operatorname{tion}^{17,18}$, was detected at $4.7 \%$. Our analysis confirms its usage by the ancient Egyptians in their beer making ${ }^{19}$ as reported by Maksoud et al. (1994) for residues recovered from another predynastic installation site, HK24A, at Hierakonpolis ${ }^{9}$. Other minor detected organic acids were malonic, acetic, malic, and hexanoic acid, which are also found in modern beer ${ }^{20,21}$. In addition, two fatty acids also known in modern brews, viz., palmitic and stearic $\operatorname{acids}^{22}$, were also detected.

Amino acids accounted for $27.4 \%$, with proline as the only major amino acid found at $25.3 \%$, making it the second most abundant acid after phosphoric acid. Ancient Egyptians are believed to have used different fruits, such as dates or figs, in their brewing process to enhance beer flavor and quality ${ }^{2}$. Maksoud et al. (1994) identified dates and grapes in the Predynastic beer residues ${ }^{9}$, although further macrobotanical analysis has not confirmed this $^{23}$. Nevertheless, the high abundance of proline may suggest that dates were added, as proline is enriched in this fruit ${ }^{24,25}$. Hydroxylamine was the main nitrogenous compound found in the beer residue at $3.1 \%$; it is a by-product of ammonia oxidation and $S$-nitrosoglutathione detoxification, part of nitrosative stress response $\mathrm{e}^{26,27}$.

GC-MS analysis of volatiles in the beer residue. Volatile analysis using solid phase microextraction (SPME) coupled to GC-MS techniques was adopted in parallel for flavor profiling and resulted in the detection of 49 volatiles belonging to 9 chemical classes, with acids (56.3\%), ketones/lactones (18.5\%), and esters (12.1\%) being the major ones alongside terpenes, nitrogenous compounds, aromatics, and aldehydes (Fig. 2C,D, Table 2). 12 Acids were detected, including nonoic, caproic, 2-methyl-butanoic, caprylic, pentanoic, heptanoic, benzoic, $\alpha$-methylbutyric, and capric acids. Interestingly, caprylic acid, capric acid, heptanoic, and nonoic acids are part of the volatile acid mixture found in modern beer $^{28,29}$. Caproic acid, a medium-chain carboxylic acids, is a product of 


\begin{tabular}{|c|c|c|c|c|c|}
\hline Peak & Rt (min) & RI & Compound Name & Class & $\begin{array}{l}\text { Average (Standard } \\
\text { Deviation) }\end{array}$ \\
\hline 1 & 4.65 & 1030 & Lactic acid $^{\mathrm{a}}$ & Acid & $3.08(0.23)$ \\
\hline 2 & 4.66 & 1031 & $\alpha$-Hydroxyisobutyric acid & Acid & $0.72(0.32)$ \\
\hline 3 & 4.66 & 1033 & Malonic acid & Acid & $3.08(0.23)$ \\
\hline 4 & 5.05 & 1041 & Acetic acid & Acid & $0.63(0.12)$ \\
\hline 5 & 5.08 & 1043 & Hexanoic acid & Acid & $0.09(0)$ \\
\hline 8 & 6.49 & 1085 & Oxalic acid $^{\mathrm{a}}$ & Acid & $4.68(2.96)$ \\
\hline 10 & 6.87 & 1095 & $\beta$-Hydroxybutyric acid & Acid & $0.02(0.01)$ \\
\hline 11 & 7.24 & 1105 & Heptanoic acid & Acid & $0.06(0.01)$ \\
\hline 14 & 8.07 & 1130 & Hydroxyisovaleric acid & Acid & $0.08(0.04)$ \\
\hline 16 & 9.34 & 1167 & Benzoic acid $^{\mathrm{a}}$ & Acid & $0.60(0.36)$ \\
\hline 19 & 10.88 & 1207 & Succinic acid ${ }^{\mathrm{a}}$ & Acid & $7.38(3.19)$ \\
\hline 21 & 11.12 & 1214 & Methyl succinic acid & Acid & $1.38(0.25)$ \\
\hline 22 & 12.07 & 1236 & Nonanoic acid & Acid & $0.02(0.01)$ \\
\hline 23 & 12.37 & 1243 & Citramalic acid & Acid & $0.56(0.31)$ \\
\hline 25 & 13.23 & 1265 & Glutaric acid & Acid & $0.85(0.27)$ \\
\hline 27 & 13.68 & 1276 & Methylglutaric acid & Acid & $0.29(0.14)$ \\
\hline 28 & 14.49 & 1295 & Citramalic acid & Acid & $0.06(0.03)$ \\
\hline 29 & 15.06 & 1309 & Malic acid ${ }^{a}$ & Acid & $0.38(0.23)$ \\
\hline 30 & 15.69 & 1323 & Adipic acid & Acid & $0.21(0.15)$ \\
\hline 33 & 18 & 1378 & Pimelic acid & Acid & $0.06(0.03)$ \\
\hline 37 & 20.12 & 1429 & Suberic acid & Acid & $1.00(0.43)$ \\
\hline 39 & 22.26 & 1479 & Azelaic acid & Acid & $0.08(0.05)$ \\
\hline \multicolumn{5}{|l|}{ Acids } & 27.76 \\
\hline 17 & 9.56 & 1173 & Glycerol $^{\mathrm{a}}$ & Alcohol & $1.60(0.48)$ \\
\hline \multicolumn{5}{|c|}{ Alcohols } & 1.60 \\
\hline 12 & 7.51 & 1113 & 16-Heptadecenal & Aldehyde & $0.37(0.18)$ \\
\hline \multicolumn{5}{|c|}{ Aldehydes } & 0.37 \\
\hline 13 & 8 & 1128 & N-Trifluoroacetyl glycine & Amino acid & $1.07(0.62)$ \\
\hline 20 & 11.12 & 1213 & Proline & Amino acid & $25.33(4.78)$ \\
\hline 24 & 12.99 & 1259 & Homocysteine & Amino acid & $0.94(0.69)$ \\
\hline 26 & 13.58 & 1271 & Unknown & Amino acid & $0.01(0)$ \\
\hline 31 & 16 & 1331 & ${\text { Pyroglutamic } \text { acid }^{\mathrm{a}}}$ & Amino acid & $0.01(0)$ \\
\hline \multicolumn{5}{|c|}{ Amino acids } & 27.36 \\
\hline 32 & 16.26 & 1337 & Di-t-butyl-trimethylsilyloxytoluene & Aromatic & $0.61(0.34)$ \\
\hline 34 & 19.77 & 1420 & Di-t-butyl-trimethylsilyloxytoluene isomer & Aromatic & $1.03(0.6)$ \\
\hline 36 & 19.92 & 1423 & Phthalic acid & Aromatic & $0.94(0.87)$ \\
\hline 40 & 22.41 & 1483 & Protocatechuic acid & Aromatic & $0.09(0.05)$ \\
\hline \multicolumn{5}{|c|}{ Aromatics } & 2.67 \\
\hline 6 & 5.4 & 1052 & Acetal & Ether & $0.85(0.45)$ \\
\hline \multicolumn{5}{|c|}{ Ethers } & 0.85 \\
\hline 42 & 27.2 & 1601 & Palmitic acid & Fatty acid & $1.23(0.12)$ \\
\hline 43 & 30.74 & 1693 & Stearic acid & Fatty acid & $2.93(0.64)$ \\
\hline \multicolumn{5}{|c|}{ Fatty acids } & 4.16 \\
\hline 18 & 9.66 & 1174 & Phosphoric acid $^{\mathrm{a}}$ & Inorganic & $26.69(8.19)$ \\
\hline 35 & 19.83 & 1421 & Unknown & Inorganic & $4.99(2.22)$ \\
\hline \multicolumn{5}{|c|}{ Inorganics } & 31.68 \\
\hline 44 & 36.18 & 1843 & Monopalmitin & Mono glyceryl ether & $0.04(0.03)$ \\
\hline 45 & 39.01 & 1925 & Monostearin & Mono glyceryl ether & $0.01(0)$ \\
\hline \multicolumn{5}{|c|}{ Mono glyceryl ethers } & 0.04 \\
\hline 7 & 5.71 & 1061 & Hydroxylamine & Nitrogenous compound & $3.14(1.24)$ \\
\hline 9 & 6.78 & 1092 & Cadaverine $^{\mathrm{a}}$ & Nitrogenous compound & $0.90(0.16)$ \\
\hline 15 & 8.47 & 1141 & Silanamine & Nitrogenous compound & $1.34(0.19)$ \\
\hline \multicolumn{5}{|c|}{ Nitrogenous compounds } & 5.37 \\
\hline 38 & 21.66 & 1465 & Deoxy mannose & Sugar & $0.01(0)$ \\
\hline 41 & 22.92 & 1495 & Myo-Inositol & Sugar & $0.64(0.32)$ \\
\hline \multicolumn{5}{|c|}{ Sugars } & 0.65 \\
\hline
\end{tabular}

Table 1. Relative percentage of silylated compounds detected in beer residues from vats using GC-MS for primary metabolites analysis $(n=4)$. Rt, Retention time; RI, Retention index. ${ }^{a}$ represents peaks confirmed by standards. The relative percentage was determined using the chromatographic peak area. The total percentile levels for each class is bolded. Number in brackets represents std deviation of measurements. 


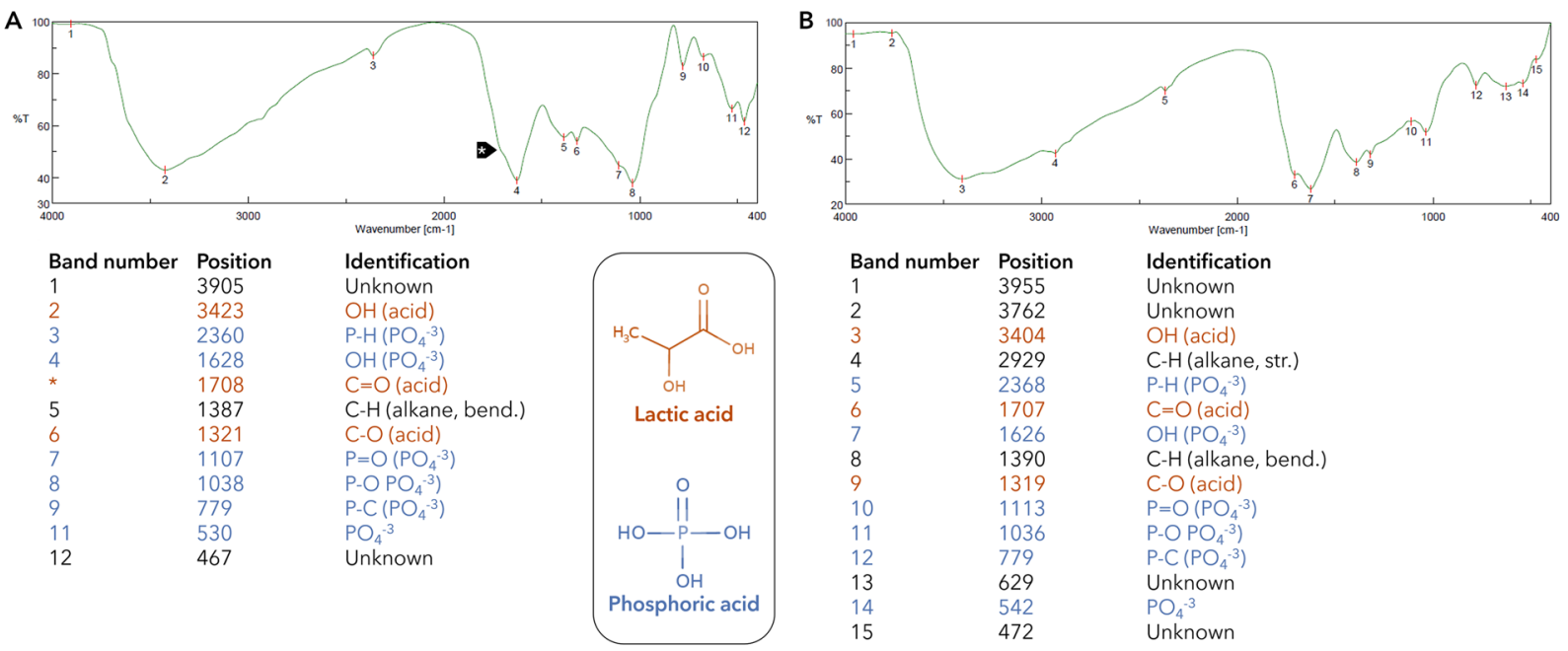

Figure 3. IR spectra from beer residue vat 1 (A) and vat 2 (B) showing IR absorption bands indicative of organic and phosphoric acid metabolites.

fermentation by yeast via chain elongation ${ }^{30}$. These fatty acids are fermentation-products and signs of beer aging and yielding a rancid or goaty flavor ${ }^{29} . \gamma$-Nonalactone was the major lactone found at $7.6 \%$ in the beer residue specimens. It exhibits a coconut-like odor and has been detected as the most odiferous compound in American bourbon whisky and other modern beers ${ }^{31-33}$. Nine esters were identified with laurate and 2-methylpropanoate esters being the major ones. Laurate and 2-methylpropanoate esters have been reported in modern beer ${ }^{20,33}$. The only major terpene that was found in the beer residues was geranyl acetone at $2 \%$, and it is also found in modern beer $^{34}$.

Archaeo-botanical analyses of remains from various locations at predynastic Hierakonpolis indicate the cultivation of barley and emmer wheat, with emmer being the predominant crop $^{35}$. Macrobotanical examination of the beer residues also suggested that emmer wheat was the major component in the beer produced at the site $e^{5,9}$. From the point of view of metabolites composition, barley and emmer wheat differ in the relative abundance of their constituents, such as their phenolics and acids, but they do not have any unique constituents that distinguish them ${ }^{36}$. Thus, it is hard to define what ratio of these grains was used in the beer. Numerous constituents of both were detected in the residue sample; however, suberic acid found at $1 \%$, glycerol at $1.6 \%$, and pyroglutamic acid $<1 \%$, have a higher abundance in wheat than barley, lending support to the macrobotanical observations.

\section{Conclusion}

The fermenting of grain-based foods is an ancient activity that goes back to nearly 13,000 years ago, even predating farming itself ${ }^{37}$. The installation at locality HK11C of Hierakonpolis is the oldest dated brewery in Egypt and one of the earliest large-scale brewing sites in the world. As our analysis of the residues from its vats suggests, over time the ancient brewers developed ways to improve the quality, taste and durability of their product, as well as the technology to produce it in large quantities. Our detailed metabolites analysis using a mass spectrometric approach for profiling the beer residue confirms that brewing was conducted at the site and provides a detailed view of the chemical makeup of the ancient beer produced there. It has revealed various organic acids and yeast fermentation products that are the signature of beer, ancient or modern. Given that the evidence for fermentation was detected in the residue obtained from the interior of the vats, the fermentation process may have taken place in the same vats after the wort had cooled down. Our analysis also indicates that fruits, such as dates, may have been added to enhance sugar content and taste. Most significantly, our analysis suggests that the Predynastic Egyptians may have already recognized the enhanced preservation imparted by the addition of barley due to its enrichment in phosphoric acid. Such an understanding would have been critical to the development of this industry, allowing the early Egyptians to produce, bottle and distribute large amounts of beer in the facility at HK11C without fear of rapid spoilage.

\section{Methods}

Materials acquisition. Materials for the analysis were the residues recovered from vats 1 and 2 at locality HK11C. Two specimens from different places at each vat were collected for metabolites analyses. The 4 samples were transferred from the site to Cairo with the permission of the Egyptian Ministry of Antiquities. Botanical observation and the radiocarbon dating were carried out at the National Research Center and the French Institute for Oriental Archaeology at Cairo. Calibration of ${ }^{14} \mathrm{C}$ age utilized IntCal 13 in the OxCal 4.3 program ${ }^{38,39}$.

Chemicals and fibers. Chemicals including standards were purchased from Sigma (St. Louis, MO, USA). A $50 / 30 \mu \mathrm{m}$ divinylbenzene/Carboxen on polydimethylsiloxane on a StableFlex fiber was used. This SPME fiber was purchased from Supelco (Oakville, ON, Canada). 


\begin{tabular}{|c|c|c|c|c|c|}
\hline Peak & Rt (min) & RI & Name & Class & $\begin{array}{l}\text { Average (Standard } \\
\text { Deviation) }\end{array}$ \\
\hline 2 & 6.43 & 873 & 2-Methyl-butanoic acid & Acid & $7.26(7.26)$ \\
\hline 3 & 6.79 & 819 & $\alpha$-Methylbutyric acid & Acid & $1.41(1.38)$ \\
\hline 4 & 7.07 & 905 & Pentanoic acid & Acid & $5.85(5.85)$ \\
\hline 5 & 7.33 & 919 & Pentanoic acid isomer & Acid & $2.80(2.74)$ \\
\hline 7 & 8.18 & 969 & Pyroterebic acid & Acid & $0.17(0.17)$ \\
\hline 8 & 8.73 & 1001 & Caproic acid & Acid & $8.31(8.07)$ \\
\hline 13 & 10.07 & 1086 & Unknown & Acid & $8.25(0.16)$ \\
\hline 14 & 10.2 & 1095 & $n$-Heptanoic acid ${ }^{\mathrm{a}}$ & Acid & $2.91(2.81)$ \\
\hline 18 & 11.28 & 1170 & Caprylic acid & Acid & $6.71(0.9)$ \\
\hline 20 & 11.57 & 1180 & Benzoic acid & Acid & $1.44(0.46)$ \\
\hline 22 & 12.49 & 1259 & Nonoic acid & Acid & $10.84(6.76)$ \\
\hline 29 & 13.61 & 1348 & $n$-Capric acid ${ }^{\mathrm{a}}$ & Acid & $0.39(0.23)$ \\
\hline \multicolumn{5}{|l|}{ Acids } & 56.31 \\
\hline 1 & 5.9 & 848 & 3-Hexen-1-ol ${ }^{\mathrm{a}}$ & Alcohol & $0.25(0.25)$ \\
\hline 23 & 12.52 & 1261 & Unknown & Alcohol & $0.83(0.27)$ \\
\hline 44 & 17.6 & 1637 & Unknown & Alcohol & $0.24(0.17)$ \\
\hline \multicolumn{5}{|c|}{ Alcohols } & 1.31 \\
\hline 12 & 9.97 & 1079 & Nonanal $^{\mathrm{a}}$ & Aldehyde & $0.17(0.17)$ \\
\hline 19 & 11.39 & 1177 & Decanal $^{\mathrm{a}}$ & Aldehyde & $0.38(0.36)$ \\
\hline \multicolumn{5}{|c|}{ Aldehydes } & 0.55 \\
\hline 6 & 7.81 & 947 & Benzaldehyde $^{a}$ & Aromatic & $0.25(0.25)$ \\
\hline 10 & 9.53 & 1052 & Acetophenone & Aromatic & $0.85(0.82)$ \\
\hline 15 & 10.95 & 1147 & o-Acetylphenol & Aromatic & $1.00(0.98)$ \\
\hline \multicolumn{5}{|c|}{ Aromatics } & 2.090 \\
\hline 25 & 13.11 & 1307 & Glycerin triacetate & Ester & $0.57(0.46)$ \\
\hline 26 & 13.32 & 1337 & 1-(2-Hydroxy-1-methylethyl)-2,2-dimethylpropyl 2-methylpropanoate & Ester & $1.06(0.53)$ \\
\hline 28 & 13.56 & 1323 & 3-Hydroxy-2,4,4-trimethylpentyl 2-methylpropanoate & Ester & $2.45(1.8)$ \\
\hline 36 & 15.39 & 1499 & Butyl maleate & Ester & $0.02(0.01)$ \\
\hline 39 & 17.15 & 1631 & Hedione & Ester & $0.81(0.27)$ \\
\hline 40 & 16.08 & 1542 & $\begin{array}{l}\text { Propanoic acid, 2-methyl-, 1-(1,1-dimethylethyl)-2-methyl-1,3-propanediyl } \\
\text { ester }\end{array}$ & Ester & $0.81(0.27)$ \\
\hline 41 & 16.13 & 1546 & unknown hydrocarbon & Ester & $0.06(0.03)$ \\
\hline 47 & 20.28 & 1778 & Isopropyl myristate & Ester & $0.21(0.13)$ \\
\hline 42 & 16.53 & 1573 & Isopropyl laurate & Ester & $6.16(5.51)$ \\
\hline \multicolumn{5}{|l|}{ Esters } & 12.13 \\
\hline 34 & 14.87 & 1451 & Pentadecane & Hydrocarbon & $0.62(0.23)$ \\
\hline 38 & 16.13 & 1599 & Hexadecane & Hydrocarbon & $0.62(0.27)$ \\
\hline 45 & 17.71 & 1642 & Unknown & Hydrocarbon & $1.76(1.2)$ \\
\hline 46 & 17.73 & 1643 & Unknown & Hydrocarbon & $0.59(0.24)$ \\
\hline \multicolumn{5}{|c|}{ Hydrocarbons } & 3.59 \\
\hline 17 & 11.2 & 1164 & 2-Decanone & Ketone & $0.24(0.24)$ \\
\hline 9 & 9.39 & 1043 & $\gamma$-Caprolactone & Lactone & $0.55(0.55)$ \\
\hline 16 & 10.83 & 1138 & $\gamma$-Heptalactone & Lactone & $0.20(0.2)$ \\
\hline 21 & 12.25 & 1241 & $\gamma$-Butylbutyrolactone & Lactone & $4.59(1.73)$ \\
\hline 27 & 13.52 & 1341 & $\gamma$-Amylbutyrolactone & Lactone & $7.56(4.33)$ \\
\hline 33 & 14.76 & 1441 & $\gamma$-Decanolactone & Lactone & $0.98(0.47)$ \\
\hline 37 & 16.08 & 1542 & $\gamma$-Decalactone & Lactone & $4.36(3.48)$ \\
\hline \multicolumn{5}{|c|}{ Ketones/Lactones } & 18.46 \\
\hline 24 & 12.58 & 1266 & Unknown & Nitrogenous compound & $2.11(1.5)$ \\
\hline \multicolumn{5}{|c|}{ Nitrogenous compounds } & 2.11 \\
\hline 30 & 13.72 & 1357 & Unknown & Terpene & $0.50(0.31)$ \\
\hline 31 & 13.95 & 1375 & Geranyl isobutyrate & Terpene & $0.04(0.02)$ \\
\hline 32 & 14.39 & 1411 & Geranyl acetone & Terpene & $2.10(1.43)$ \\
\hline 35 & 14.94 & 1457 & Aromandendrene & Terpene & $0.12(0.03)$ \\
\hline 43 & 17.48 & 1631 & Unknown & Terpene & $0.20(0.11)$ \\
\hline 48 & 20.57 & 1794 & Hexahydrofarnesyl acetone & Terpene & $0.16(0.07)$ \\
\hline
\end{tabular}




\begin{tabular}{|l|l|l|l|l|l|}
\hline Peak & Rt $(\mathbf{m i n})$ & RI & Name & Class & $\begin{array}{l}\text { Average (Standard } \\
\text { Deviation) }\end{array}$ \\
\hline 49 & 21.44 & 1878 & Farnesyl acetone & Terpene & $0.10(0.03)$ \\
\hline \multicolumn{7}{|l|}{} & Unknown & $\mathbf{3 . 2 0}$ \\
\hline 11 & 9.59 & 1056 & Unknown & 0.27 \\
\hline
\end{tabular}

Table 2. Relative percentage of compounds detected in beer residues from vats using SPME-GC-MS for volatiles analysis $(n=3)$. Rt, Retention time; RI, Retention index. ${ }^{a}$ represents peaks confirmed by standards. The relative percentage was determined using the chromatographic peak area. The total percentile levels for each class is bolded. Number in brackets represents std deviation of measurements.

Analysis of silylated primary metabolites. To analyze non-volatile primary metabolites, we followed our previously described protocol in Farag et al. $(2017)^{40}$. First, a $100-\mu \mathrm{L}$ of $70 \%$ aqueous extract was prepared. This was achieved by extracting $100 \mathrm{mg}$ of residue powder with $5 \mathrm{~mL}$ of $50 \%$ methanol with sonication for $30 \mathrm{~min}$, which was followed by centrifugation at $12,000 \mathrm{~g}$ for $5 \mathrm{~min}$ to remove any debris. Then, the $70 \%$ aqueous extract was evaporated under nitrogen until dryness. For derivatization by silylation, a $150-\mu \mathrm{L}$ of $N$-methyl- $N$ (trimethylsilyl)-trifluoroacetamide (MSTFA) was added to the dried extract and incubated for $45 \mathrm{~min}$ at $60^{\circ} \mathrm{C}$. The samples were equilibrated at $28^{\circ} \mathrm{C}$ and subsequently analyzed using gas chromatography-mass spectrometry (GC-MS). A Trace GC Ultra Gas Chromatograph, coupled with a Thermo Scientific ISQ Single Quadrupole Mass Spectrometer (Thermo Scientific Corp., USA), was used for profiling of non-volatile silylated metabolites. Chromatographic separation was achieved on a Rtx-5MS column ( $30 \mathrm{~m}$ (length) $\times 0.25 \mathrm{~mm}$ (inner diameter), $0.25 \mu \mathrm{m}$ film thickness) to analyze derivatized bear residual samples. Injections were performed in a split mode (1:15) and the gas chromatograph was operated as follows: injector temperature at $280^{\circ} \mathrm{C}$, column oven temperature at $80^{\circ} \mathrm{C}$ for $2 \mathrm{~min}$, followed by a program at a rate of $5^{\circ} \mathrm{C} / \mathrm{min}$ until $315^{\circ} \mathrm{C}$, and kept at $315^{\circ} \mathrm{C}$ for $12 \mathrm{~min}$; Helium carrier gas at rate $1 \mathrm{~mL} / \mathrm{min}$. The transfer line and ion-source temperatures were adjusted at $280^{\circ} \mathrm{C}$ and $180^{\circ} \mathrm{C}$, respectively. The mass spectrometer was run in electron ionization mode at $70 \mathrm{eV}$. The scan range used was $50-650 \mathrm{~m} / \mathrm{z}$. Metabolites were identified using the procedure detailed in Farag and Wessjohann $(2012)^{41}$. For metabolite identification, peaks were deconvoluted using AMDIS software and identified using the following approaches: retention indices $(\mathrm{RI})$ relative to $n$-alkanes $\left(\mathrm{C}_{6}-\mathrm{C}_{20}\right)$, mass spectrum matching to National Institute of Standards and Technology (NIST) and WILEY libraries, and available authentic standards. Relative percentages of metabolites were determined based on individual metabolite peak area relative to the sum of all identified metabolites peak areas.

Volatiles isolation by SPME method. Headspace volatiles analysis using solid-phase microextraction (SPME) was adopted from Farag et al. (2015) with a few modifications ${ }^{42}$. Briefly, residue from vats was ground, and a $200-\mathrm{mg}$ was placed in a $1.5-\mathrm{mL}$ glass vial. (Z)-3-Hexenyl acetate, absent from specimens' volatile organic compounds, was used as an internal standard. (Z)-3-Hexenyl acetate was dissolved in water and added at a concentration of $10 \mu \mathrm{g} / \mathrm{vial}$. Then, vials were immediately capped and the SPME fibers were inserted into the headspace above the sample. Finally, vials were placed on a temperature-controlled tray at $50{ }^{\circ} \mathrm{C}$ for $30 \mathrm{~min}$ to achieve optimum adsorption. A system blank was run as a control. This blank sample was run from an empty vat containing no organic residue.

Analysis of volatiles collected using SPME. SPME-isolated volatiles were subsequently analyzed using GC-MS. SPME fibers were desorbed at $210^{\circ} \mathrm{C}$ for $1 \mathrm{~min}$ in the injection port of a Shimadzu Model GC-17A gas chromatograph interfaced with a Shimadzu model QP5000 mass spectrometer (Japan). Volatiles were separated on an Agilent J\&W DB-5ms column, $30 \mathrm{~m}$ (length), $0.25 \mathrm{~mm}$ (inner diameter), $0.25 \mu \mathrm{m}$ (film) (Agilent Technologies, Santa Clara, CA, USA). Injections were performed in the splitless mode for $30 \mathrm{~s}$. The gas chromatograph was operated as follows: injector temperature at $220^{\circ} \mathrm{C}$, column oven temperature at $38^{\circ} \mathrm{C}$ for $3 \mathrm{~min}$, then programmed at a rate of $12^{\circ} \mathrm{C}$ per min to $180^{\circ} \mathrm{C}$, kept at $180^{\circ} \mathrm{C}$ for $5 \mathrm{~min}$, finally ramped at a rate of $40^{\circ} \mathrm{C}$ per min until $220^{\circ} \mathrm{C}$ and kept there for $2 \mathrm{~min}$; Helium carrier gas at $1 \mathrm{~mL} / \mathrm{min}$. The transfer line and ion-source temperatures were adjusted under analysis of silylated primary metabolites. The mass spectrometer was operated as previously described under analysis of silylated primary metabolites, except for the scan range, which was set at $40-500 \mathrm{~m} / \mathrm{z}$. Volatile metabolites were identified as previously described under analysis of silylated primary metabolites.

IR analysis. Residue samples were weighed to be in a specific mass, then mixed with spectroscopic grade of dried potassium bromide, obtained from Specac (UK) to obtain proper weight/weight concentration of sample/diluent. Prepared pellets were placed in a Fourier-transform infrared spectrophotometer (Jasco FT/IR-6100, Japan). Spectra, for each sample, were recorded in the range of $4000-400 \mathrm{~cm}^{-1}$, scanning resolution of $4 \mathrm{~cm}^{-1}, 256$ single scans, and initial delay of $300 \mathrm{~s}$. For each set of analysis, clear potassium bromide was used as a background.

Abbreviations. BCE, Before Common Era; BP, Before Present; SPME, solid phase microextraction; GC, gas chromatography; MS, mass spectrometry; RI, retention index; MSTFA, N-methyl-N-(trimethylsilyl)-trifluoro acetamide; PCA, principal component analysis; HCA, hierarchical clustering analysis; NIST, National Institute of Standards and Technology; IS, internal standard; IR, infrared. 


\section{Data availability}

All data are presented in the main text. Raw data is available at MetaboLights under MTBLS1302 study (www.ebi. ac.uk/metabolights/MTBLS1302) ${ }^{43}$.

Received: 3 March 2019; Accepted: 9 October 2019; Published online: 07 November 2019

\section{References}

1. Adamski, B. \& Rosińska-Balik, K. In The Nile Delta as a centre of cultural interactions between Upper Egyptand the Southern Levant in the 4th millennium BC (ed. Mączyńska, A.) 23-36 (Poznań Archaeological Museum, 2014).

2. Samuel, D. In Ancient Egyptian Materials And Technology (eds Nicholson, P. T. \& Shaw, I.) 537-576 (Cambridge University Press, 2000).

3. Friedman, R. In Before the Pyramids: The Origins of Egyptian Civilization (ed. Teeter, E.) 33-44 (Oriental Institute of the University of Chicago, 2011).

4. Baba, M. \& Friedman, R. In Egypt atits Origins 4: Proceedings of the Fourth International Conference "Origin ofthe State. Predynastic and Early Dynastic Egypt (eds Adams, M. D., Midant-Reynes, B., Ryan, E. M. \& Tristant, Y.) 179-205 (Peeters, 2016).

5. Attia, E. A. E., Marinova, E., Fahmy, A. G. \& Baba, M. In Plants and people in the african past: progress in african archaeobotany (eds Mercuri, A. M., D’Andrea, A. C., Fornaciari, R. \& Höhn, A.) 76-89, https://doi.org/10.1007/978-3-319-89839-1_5 (Springer International Publishing, 2018).

6. Lindley, E. et al. Use of a standard urine assay for measuring the phosphate content of beverages. J Ren Nutr 24, 353-356 (2014).

7. Wickham, E. Phosphorus content in commonly consumed beverages. J Ren Nutr 24, e1-e4 (2014).

8. Moser, M. et al. Phosphorus content of popular beverages. Am. J. Kidney Dis. 65, 969-971 (2015).

9. Maksoud, S. A., El Hadidi, M. N. \& Amer, W. M. Beer from the early dynasties (3500-3400 cal B.C.) of Upper Egypt, detected by archaeochemical methods. Veg. Hist. Archaeobot. 3, 219-224 (1994).

10. Drozdowicz, Y. M. \& Jones, R. L. Hormonal regulation of organic and phosphoric acid release by barley aleurone layers and scutella. Plant Physiol. 108, 769-776 (1995).

11. Schönberger, C. \& Kostelecky, T. 125th anniversary review: the role of hops in brewing. J. Inst. Brew. 117, 259-267 (2011).

12. Matthews, C. G. \& Woolcott, G. H. The Phosphoric Acid in Barley and Malt, with some Notes on the presence of Organic Acids in Malt. J. of the Federated Institutes of Brewing 4, 6-22 (1898).

13. Flavours of Their Time. Minoans and Mycenaeans: Flavours of Their Time. (Production Kapon Editions, 1999).

14. Coote, N. \& Kirsop, B. H. The content of some organic acids in beer and other fermented media. J. Inst. Brew. 80, 474-483 (1974).

15. Li, H. \& Liu, F. Changes in Organic Acids during Beer Fermentation. ASBCJ 73, 275-279 (2015).

16. Park, J.-M., Shin, J.-A., Lee, J. H. \& Lee, K.-T. Development of a quantitative method for organic acid in wine and beer using high performance liquid chromatography. Food Sci Biotechnol 26, 349-355 (2017).

17. Michel, R. H., McGovern, P. E. \& Badler, V. R. Chemical evidence for ancient beer. Nature 360, 24-24 (1992).

18. Wang, J. et al. Revealing a 5,000-y-old beer recipe in China. Proc. Natl. Acad. Sci. USA 113, 6444-6448 (2016).

19. Brudzyński, A. \& Salamon, A. The Oxalic Acid Content in Selected Barley Varieties Grown in Poland, as well as in their Malts and Worts. J. Inst. Brew. 117, 67-73 (2011)

20. Belke, C. J. \& Irwin, A. J. Determination of Organic Acids in Beer After Extraction with an Anion-Exchange Resin. ASBCJ 50, 26-29 (1992).

21. Klopper, W. J., Angelino, S. A. G. F., Tuning, B. \& Vermeire, H. A. Organic acids and glycerol in beer. J. Inst. Brew. 92, 225-228 (1986).

22. Bravi, E., Marconi, O., Sileoni, V. \& Perretti, G. Determination of free fatty acids in beer. Food Chem. 215, 341-346 (2017).

23. McGOVERN, P. E. Uncorking the Past: The Quest for Wine, Beer, and Other Alcoholic Beverages. 241-2 (University of California, 2009).

24. Hamad, I. et al. Metabolic Analysis of Various Date Palm Fruit (Phoenix dactylifera L.) Cultivars from Saudi Arabia to Assess Their Nutritional Quality. Molecules 20, 13620-13641 (2015).

25. Assirey, E. A. R. Nutritional composition of fruit of 10 date palm (Phoenix dactylifera L.) cultivars grown in Saudi Arabia. J. of Taibah University for Science 9, 75-79 (2015).

26. Gilch, S., Meyer, O. \& Schmidt, I. A soluble form of ammonia monooxygenase in Nitrosomonas europaea. Biol. Chem. 390, 863-873 (2009).

27. Liu, L. et al. A metabolic enzyme for S-nitrosothiol conserved from bacteria to humans. Nature 410, 490-494 (2001).

28. Clarke, B. J., Harold, F. V., Hildebrand, R. P. \& Morieson, A. S. Trace volatile constituents of beer iv. volatile acids. J. Inst. Brew. 68, 179-187 (1962).

29. Horák, T. et al. Analysis of free fatty acids in beer: comparison of solid-phase extraction, solid-phase microextraction, and stir bar sorptive extraction. J. Agric. Food Chem. 57, 11081-11085 (2009).

30. Ge, S., Usack, J. G., Spirito, C. M. \& Angenent, L. T. Long-Term n-Caproic Acid Production from Yeast-Fermentation Beer in an Anaerobic Bioreactor with Continuous Product Extraction. Environ. Sci. Technol. 49, 8012-8021 (2015).

31. Garbe, L. A., Lange, H. \& Tressl, R. In Aroma active compounds in foods: chemistry and sensory properties (eds Takeoka, G. R., Güntert, M. \& Engel, K.-H.) 794, 176-182 (American Chemical Society, 2001).

32. Poisson, L. \& Schieberle, P. Characterization of the most odor-active compounds in an American Bourbon whisky by application of the aroma extract dilution analysis. J. Agric. Food Chem. 56, 5813-5819 (2008).

33. Tsuji, H. \& Mizuno, A. Volatile compounds and the changes in their concentration levels during storage in beers containing varying malt concentrations. J. Food Sci. 75, C79-84 (2010).

34. Hoff, S., Lund, M. N., Petersen, M. A., Frank, W. \& Andersen, M. L. Storage stability of pasteurized non-filtered beer. J. Inst. Brew, https://doi.org/10.1002/jib.85 (2013).

35. Fahmy, A., Friedman, R. \& Fadl, M. A. In Windows on the African Past. Current Approaches to African Archaeobotany (eds Fahmy, A. G., Kahlheber, S. \& D’Andrea, C.) 91-118 (Africa Magna Verlag, 2011).

36. Khakimov, B., Jespersen, B. M. \& Engelsen, S. B. Comprehensive and Comparative Metabolomic Profiling of Wheat, Barley, Oat and Rye Using Gas Chromatography-Mass Spectrometry and Advanced Chemometrics. Foods 3, 569-585 (2014).

37. Liu, L. et al. Fermented beverage and food storage in 13,000 y-old stone mortars at Raqefet Cave, Israel: Investigating Natufian ritual feasting. J. of Archaeological Science: Reports 21, 783-793 (2018).

38. Reimer, P. et al. IntCal13 and Marine13 Radiocarbon Age Calibration Curves 0-50,000 Years cal BP. Radiocarbon 55, 1869-1887 (2013).

39. Ramsey, C. B. Methods for summarizing radiocarbon datasets. Radiocarbon 59, 1809-1833 (2017).

40. Farag, M. A., Fahmy, S., Choucry, M. A., Wahdan, M. O. \& Elsebai, M. F. Metabolites profiling reveals for antimicrobial compositional differences and action mechanism in the toothbrushing stick "miswak" Salvadora persica. J. Pharm. Biomed. Anal. 133, 32-40 (2017).

41. Farag, M. A. \& Wessjohann, L. A. Volatiles profiling in medicinal licorice roots using steam distillation and solid-phase microextraction (SPME) coupled to chemometrics. J. Food Sci. 77, C1179-84 (2012). 
42. Farag, M. A., Rasheed, D. M. \& Kamal, I. M. Volatiles and primary metabolites profiling in two Hibiscus sabdariffa (roselle) cultivars via headspace SPME-GC-MS and chemometrics. Food Res. Int. 78, 327-335 (2015).

43. Haug, K. et al. MetaboLights-an open-access general-purpose repository for metabolomics studies and associated meta-data. Nucleic Acids Res. 41, D781-6 (2013).

\section{Acknowledgements}

We would like to express our deepest appreciation to all members of the Egyptian Ministry of Antiquities, in particular to Dr. Khaled El-Anany (the Minister of Antiquities) for granting us the permission for our works. Thanks are also due to Dr. Dalia Ahmed Meligy and Dr. Ashraf Nageh (Research and Conservation Center of Antiquities) who kindly supported our researches in Cairo. Current research is supported by JSPS KAKENHI (Grant Number 16K03167).

\section{Author contributions}

M.A.F. performed the chemical analysis, interpreted results and revised the paper. M.M.E. performed the statistical analysis, interpreted results, prepared figures and wrote the paper. M.B. discovered the beer site, provided specimens and revised the paper. R.F. directed the Hierakonpolis Expedition and revised the paper. All authors reviewed the manuscript.

\section{Competing interests}

The authors declare no competing interests.

\section{Additional information}

Correspondence and requests for materials should be addressed to M.B.

Reprints and permissions information is available at www.nature.com/reprints.

Publisher's note Springer Nature remains neutral with regard to jurisdictional claims in published maps and institutional affiliations.

(c) (i) Open Access This article is licensed under a Creative Commons Attribution 4.0 International License, which permits use, sharing, adaptation, distribution and reproduction in any medium or format, as long as you give appropriate credit to the original author(s) and the source, provide a link to the Creative Commons license, and indicate if changes were made. The images or other third party material in this article are included in the article's Creative Commons license, unless indicated otherwise in a credit line to the material. If material is not included in the article's Creative Commons license and your intended use is not permitted by statutory regulation or exceeds the permitted use, you will need to obtain permission directly from the copyright holder. To view a copy of this license, visit http://creativecommons.org/licenses/by/4.0/.

(C) The Author(s) 2019 